EGU2020-6894

https://doi.org/10.5194/egusphere-egu2020-6894

EGU General Assembly 2020

(c) Author(s) 2020. This work is distributed under

the Creative Commons Attribution 4.0 License.

\title{
Composite data set of last glacial Dansgaard/Oeschger events obtained from stable oxygen isotopes in speleothems
}

\author{
Jens Fohlmeister ${ }^{1}$, Niklas Bores ${ }^{1}$, Norbert Marwan ${ }^{1}$, Andrea Columbu ${ }^{2}$, Kira Rehfeld ${ }^{3}$, Natasha \\ Sekhon ${ }^{4}$, Louise Sime ${ }^{5}$, and Cristina Veiga-Pires ${ }^{6}$ \\ ${ }^{1}$ Potsdam Institute for Climate Impact Research, Telegrafenberg, 14473 Potsdam, Germany \\ ${ }^{2}$ University of Bologna, Department of Biological, Geological and Environmental Sciences, Via Zamboni 67, 40126 Bologna, \\ Italy \\ ${ }^{3}$ Institute of Environmental Physics, University of Heidelberg INF 229, 69120 Heidelberg, Germany \\ ${ }^{4}$ Department of Geological Sciences, Jackson School of Geosciences, University of Texas, Austin, TX 78712, USA \\ ${ }^{5}$ Ice Dynamics and Palaeoclimate, British Antarctic Survey, Cambridge CB3 OET, UK \\ ${ }^{6}$ Universidade do Algarve, CIMA-UAlg, Campus de Gambelas, 8005-139 Faro, Portugal
}

Millennial scale climate variations called Dansgaard-Oeschger cycles occurred frequently during the last glacial, with their central impact on climate in the North Atlantic region. These events are, for example, well captured by the stable oxygen isotope composition in continental ice from Greenland, but also in records from other regions. Recently, it has been shown that a water isotope enabled general circulation model is able to reproduce those millennial-scale oxygen isotope changes from Greenland (Sime et al., 2019). On a global scale, this isotope-enabled model has not been tested in its performance, as stable oxygen isotope records covering those millennial scale variability were so far missing or not systematically compiled.

In the continental realm, speleothems provide an excellent archive to store the oxygen isotope composition in precipitation during those rapid events. Here, we use a newly established speleothem data base (SISAL, Atsawawaranunt et al., 2018) from which we extracted 126 speleothems, growing in some interval during the last glacial period. We established an automated method for identification of the rapid onsets of interstadials. While the applied method seems to be not sensitive enough to capture all warming events due to the diverse characteristics of speleothem data (temporal resolution, growth stops and dating uncertainties) and low signal-tonoise-ratio, we are confident that our method is not detecting variations in stable oxygen isotopes that do not reflect stadial-interstadial transitions. Finally, all found transitions were stacked for individual speleothem records in order to provide a mean stadial-interstadial transition for various continental locations. This data set could be useful for future comparison of isotope enabled model simulations and corresponding observations, and to test their ability in modelling millennial scale variability. 
Atsawawaranunt, et al. (2018). The SISAL database: A global resource to document oxygen and carbon isotope records from speleothems. Earth System Science Data 10, 1687-1713

Sime, L. C., Hopcroft, P. O., Rhodes, R. H. (2019). Impact of abrupt sea ice loss on Greenland water isotopes during the last glacial period. PNAS 116, 4099-4104. 